\title{
Study on the Soil and Plant Community Characteristics at an Early Ecological Restoration Stage in an Abandoned Quarry
}

\author{
Qiong Wang ${ }^{1, ~ a ~, ~ Z a i y u a n ~} \mathrm{Gu}^{2, \mathrm{~b}}$ and Lianbi Zhou ${ }^{1, \mathrm{c}}$ \\ ${ }^{1}$ Beijing General Research Institute of Mining \&Metallurgy, China \\ ${ }^{2}$ Beijing Fountain of Green Eco-Tech Co.,Ltd., China \\ awangqiong426@126.com, b531040484@qq.com, 'choulianbi@aliyun.com
}

\begin{abstract}
Keywords: abandoned quarry; ecological restoration; plant community; a diversity indexes Abstract. Taking an abandoned quarry located in Chengang town of Zhoushan city as an example and on the basis of investigating into vegetation and soil condition, the physicochemical properties of soil and plant community characteristics are analyzed. The results indicate: the physicochemical properties of the four types of the disused lands of the quarry are very poor; the nutrient condition of abandoned quarry area is also poor, they are the main limiting factor to ecological restoration. The main types of vegetation in this area are grassland. The woody species are rather singular with only 5 families, 7 genera and 7 species, but the herb communities are much more abundant with 5 families, 24 genera and 27 species in total. The changes of $\alpha$ diversity indexes to four types of the abandoned lands of quarry are quite different, the order of the species richness indexes to different types of the abandat quarry from big to small was spoil mound, stone-soil stack, worked-out area and terrace for crush. While the species diversity and species richness indexes are worked-out area, stone-soil stack, spoil mound and terrace for crush.
\end{abstract}

\section{Introduction}

With the constant development of the economy and society, the construction scale of real estates and urban infrastructures, and as well as expressways and railways, the demands of stone materials are increasing rapidly. However, unreasonable quarrying resulted in a great number of abandoned quarries $^{[1]}$. Abandoned quarry is an extremely degraded ecological system formed under serious interference of human factors. The dramatic reduction, degradation and even vanishing of original vegetation due to drastic change of ecological environment, and this seriously impacts the sustainable development of the society and economy ${ }^{[2,3]}$. Therefore, vegetation restoration of abandoned quarries has become a hot topic of ecological restoration and landscape ecology research ${ }^{[4,5]}$. herefore, many countries attempt to take various techniques and measures to restore quarries according to different conditions, for example, covering the land of abandoned quarries with the original surface soil ${ }^{[6]}$, introducing local plants (particularly legumes) to the land of abandoned quarries ${ }^{[7]}$, taking the method of hydro seeding and technique of landform replication, etc to facilitate vegetation restoration of abandoned quarries. It's very important to be aware of the basic information about the land of abandoned quarries and the situation of early natural invasion. In this research, Damiao Quarry of Cen'gang Town, Zhoushan City, is taken as an example, to research and analyze the characteristics of the soil and plant community structure during the process of natural restoration, aiming to provide a theoretical basis for further acceleration of artificial plant restoration and reduction of the restoration cost.

\section{Materials and methods}

Survey of the place under research. The Quarry is located in Cen'gang Town of Zhoushan City, geographical coordinates: $122^{\circ} 06^{\prime} 15^{\prime \prime} \sim 122^{\circ} 09^{\prime} 30^{\prime \prime}$ east longitude, $30^{\circ} 01^{\prime} 00^{\prime \prime} \sim 30^{\circ} 02^{\prime} 35^{\prime \prime}$ north latitude. It's located in the subtropical monsoon region in the east continent, belonging to subtropical monsoon marine climate, featuring four distinct seasons, warm and humid, abundant rainfall, remarkable monsoon, etc. The quarry under survey has been closed for nearly 10a, the mount body 
has been seriously damaged, and the rock strata have been etched to different degrees. Through nearly 10a natural succession, the vegetation has been dominated by drought-tolerant and anti-barren Gramineae herbaceous plants, mainly including Setaria virids (L.) Beauv., Miscanthus floridulu (Labnll.)Warb, Phytolacca acinosa Roxb., Setaria fabeii Herrm., etc. There are sparse woody plants in the worked-out area, dominated by Vitex negundo Linn. var. heterophylla.

Research method. Based on on-spot-survey and combining the site characteristics of Damiao Quarry, the quarries are classified into 4 types, i.e. spoil mound, worked-out area, stone-soil stack and terrace for crush.

Collection of soil samples: 20 subquadrats are taken on 4 types of quarries randomly, and the sampling area is $10 \times 10 \mathrm{~cm}^{2} .0 \sim 5 \mathrm{~cm}$ soil is collected for testing the physicochemical properties of soil, including particle sizes of $5 \mathrm{~mm}, 2 \mathrm{~mm}, 1 \mathrm{~mm}$ and $0.5 \mathrm{~mm}$, the vegetations growing well around are taken for comparison. The mechanical composition, $\mathrm{pH}$, organic matters, hydrolyzable nitrogen, available phosphorus and available potassium are tested.

Vegetation survey: According to the size of the site of survey and the number of quadrats decided in accordance with the stroma condition, 20 quadrats are set on the disused land of barrow pit, 12 are set on the stone-soil stack and terrace for crush respectively, 15 are set on the spoil mound, 59 in total. The quadrat for arbor is $5 \mathrm{~m} \times 5 \mathrm{~m}, 3 \mathrm{~m} \times 3 \mathrm{~m}$ for shrub, and $1 \mathrm{~m} \times 1 \mathrm{~m}$ for herbs. The items under survey include species composition, number of individuals, growth height and coverage degree of the community.

Importance value of community:

Importance value of arbor $\mathrm{IV}_{\text {arbor }}=($ relative height + relative frequency + relative dominance $) / 300$

Importance value of shrub $\mathrm{IV}_{\text {shrub }}=$ (relative height + relative abundance + relative frequency $) / 300$

Importance value of herb $\mathrm{IV}_{\text {herb }}=$ (relative height + relative coverage + relative frequency) $/ 300$

$\alpha$ diversity index: According to the method for diversity measurement of plant community reviewed by Ma Keping and Zhang Jintun ${ }^{[8-10]}$, and the following 6 indexes are taken for measurement:

Shannon-Wienerd diversity index $\left(H^{\prime}\right) H^{\prime}=-\sum P_{i} l n P_{i}$

Simpson diversity index $(D) \quad D=1-\sum\left(P_{i}\right)^{2}$

Pielou homogeneity index $(\mathrm{Jp})$

Alatalo homogeneity index $(E a)$

$$
\begin{aligned}
& \left.J p=-\sum P_{i}\right] n P_{i} / \operatorname{LnS} \\
& E a=\left[\left(\sum P_{i}{ }^{2}\right)^{-1}-1\right] /\left[\exp \left(-\sum P_{i} \operatorname{Ln} P_{i}\right)-1\right] \\
& M a=(S-1) / \operatorname{LnN}
\end{aligned}
$$

Margalef richness index $(M a) \quad M a=(S-1) / \operatorname{LnN}$

In the equation: $S$ indicates the total number of plant species in the quadrat area of community; $N$ indicates the total number of individuals of all species in the community; $P_{i}=N_{i} / N, N_{i}$ indicates the number of individuals of the $i$ th species in the quadrat.

\section{Result and analysis}

Physicochemical properties of abandoned quarry. Mechanical composition of soil is a stable natural property, which determines the character of soil and decides the status that land utilizes the mechanical composition of soil to affect soil moisture, air and heat, and meanwhile, affect the conversion of nutrients. It's indicated in Table 1 that gravel (particle size: 10-1mm) contents of spoil mound, worked-out area, stone-soil stack and terrace for crush are 30.8\%, 52.9\%, 63.3\% and 73.9\% respectively. On balance, the quarry is mainly composed of gravels (particle size: $10-1 \mathrm{~mm}$ ), covering $55.2 \%$; however, the gravel content of the vegetation area around the disused land is only $15.4 \%$. As can be seen, abandoned quarry is an extremely inferior site, not favorable for the growth of plants.

According to the result of soil nutrient measurement of the vegetation area growing well around the disused land before test: the soil nutrients are relatively poor compared with the soil nutrients in the check plot. If the average value of organic matters is $9.38 \%$ of that of the check plot, only $4.29 \%$ for hydrolyzable nitrogen, only $6.14 \%$ for rapid available potassium, and only $9.86 \%$ for rapid 
available phosphorus. On balance, the nutrient status of the 4 types of disused land is very poor, and poor soil nutrient condition is one of the key reasons for difficult vegetation restoration of abandoned quarries.

Table1. The selected physico-chemical properties of four types of disused lands of quarry

\begin{tabular}{|c|c|c|c|c|c|c|c|c|c|c|}
\hline & \multicolumn{5}{|c|}{ Mechanical composition of soil (\%) } & \multirow{2}{*}{$\begin{array}{c}\text { Organic } \\
\text { matters } \\
\%\end{array}$} & \multirow{2}{*}{$\begin{array}{c}\text { Hydrolyzable } \\
\text { nitrogen } \\
\mathrm{mg} \cdot \mathrm{kg}^{-1}\end{array}$} & \multirow{2}{*}{$\begin{array}{l}\text { Available } \\
\text { phosphoru } \\
\mathrm{s} \mathrm{mg} \cdot \mathrm{kg}^{-1}\end{array}$} & \multirow{2}{*}{$\begin{array}{c}\text { Available } \\
\text { potassium } \\
\mathrm{mg} \cdot \mathrm{kg}^{-1}\end{array}$} & \multirow[b]{2}{*}{$\mathrm{PH}$} \\
\hline & $\begin{array}{c}> \\
5 \mathrm{~mm}\end{array}$ & $\begin{array}{l}2 \sim 5 \\
\mathrm{~mm}\end{array}$ & $\begin{array}{l}1 \sim 2 \\
\mathrm{~mm}\end{array}$ & $\begin{array}{c}0.5 \sim 1 \\
\mathrm{~mm}\end{array}$ & $<0.5 \mathrm{~mm}$ & & & & & \\
\hline Spoil mound & 7.2 & 14.3 & 9.3 & 10.3 & 58.9 & 1.36 & 2.11 & 0.98 & 3.43 & 6.1 \\
\hline Worked-out area & 38.8 & 19.2 & 7.9 & 11.6 & 22.5 & 1.65 & 3.01 & 1.42 & 4.91 & 6.7 \\
\hline Stone-soil stack & 35.4 & 16.1 & 11.8 & 9.8 & 26.9 & 0.96 & 1.31 & 0.92 & 2.11 & 6.8 \\
\hline $\begin{array}{l}\text { Terrace for crush } \\
\text { Vegetation area }\end{array}$ & 52.9 & 13.9 & 7.1 & 6.5 & 19.6 & 0.65 & 1.05 & 0.21 & 1.85 & 6.6 \\
\hline $\begin{array}{l}\text { Vegetation area } \\
\text { around the disused } \\
\text { land }\end{array}$ & 0.0 & 5.2 & 10.2 & 18.2 & 66.4 & 12.31 & 43.55 & 10.55 & 50.11 & 7.1 \\
\hline
\end{tabular}

Composition of species and structural characteristics. Composition of species is one of the characteristics of plant community, and the foundation for the formation of a community. It can reflect the structure, dynamic properties and other basic characteristics of the community, and indicates the basic law of community. A indicates spoil mound, B indicates worked-out area, C indicates stone-soil stack and D indicates terrace for crush. A community survey was conducted in Damiao Quarry which has been abandoned. During the 10a natural succession, there are only a small number of woody and vine plants, which are mainly herbaceous plants. Therein, woody plants are very singular, only exist 4 dungarunga species and 3 shrub species, covering $17.07 \%$ of the total species. There are 4 vine species and 3 fern species, covering $9.76 \%$ and $7.32 \%$ of the total species respectively. Compared with woody, vine and fern plants, the composition of herbaceous community are relatively rich, in 5 families, 24 genera and 27 species. Therein, the Compositae and Compositae plants are the most, covering 40.74 and $37.04 \%$ of the total number of herbaceous plants, among which, most are herbaceos perennial, covering $59.26 \%$.

As far as site types are concerned, the 4 types of disused lands have plant invasion to different extents. As the terrace for crush is mainly composed of crushed stones and dusts and repetitively rolled over by stone-transporting vehicles, the ground surface is very solid and not favorable for the growth of plant. As a result, the vegetation is the poorest on the terrace of crush, with only some sparse plants and the structure is very simple. There are only 4 families, 8 genera and 8 species, therein, mainly including herbaceous plants, covering $87.5 \%$. The vegetation on the spoil mound and stone-soil stack is better than that on the terrace of crush, with 7 families, 11 genera and 12 species on the spoil mound and 9 families, 15 genera and 15 species on the stone-soil stack, and there are sparse dungarunga and vine plants. Compared with the former 3 types of disused lands, the vegetation in the worked-out area is the best, with relatively abundant plant composition, including 12 families, 24 genera and 25 species of plants, but still dominated by herbaceous plants, covering $60 \%$, followed by woody plants (trees and shrubs), accounting for $20 \%$.

As can be seen, the natural vegetation restoration of the abandoned Damiao Quarry is relatively slow, and Compositae and Gramineae are the dominant families in the initial stage of succession at the quarry.

Importance value of community. During the research of forest community, J. T. Crutis and R. P. McIntosh (1951) put forward the concept of importance value to decide the relative importance of each tree species in the plant community. Importance value is an important basis reflecting the role and status of plants in the entire community. Through calculation, species with importance value $>1$ are selected and listed in descending order in Table 3. As seen in Table 3, the role of the dominant population of the vegetation community on the disused land of the 4 types of sites is remarkable, therein, plants with importance value $>1$ in the communities of spoil mound and terrace for crush are 3 species and 2 species respectively. Among which, Setaria virids (L.) Beauv. population is dominant, with importance values being 5.937 and 2.889 respectively. But it's different for accompanying species, the former is accompanied by Setaria fabeii Herrm. and Solidago decurrens Lour., indicated 
as Setaria virids (L.) Beauv. + Solidago decurrens Lour. + Artemisia lavandulaefolia DC community, but the latter is accompanied by Fimbristylis hookeriana Bocklr., indicated as Setaria virids (L.) Beauv. + Fimbristylis hookeriana Bocklr; the community of the worked-out area is dominated by Miscanthus floridulu (Labnll.)Warb, with importance value being 2.017, mainly accompanied by Vitex negundo Linn. var. heterophylla Rehd., Setaria virids (L.) Beauv., Imperatacy lindrica var. major, therein, 5 species of plants with importance value $>1$; in the community on stone-soil stack, Phytolacca acinosa Roxb. is a dominant species, Artemisia annua Linn., Artemisia lavandulaefolia DC and Salsola collina Pall. are accompanying species, indicated as Artemisia annua Linn. + Artemisia lavandulaefolia DC + Salsola collina Pall., therein, the importance value of dominant species is as high as 3.043 , and there are 4 plant species with importance value $>1$.

$\boldsymbol{\alpha}$ diversity index of community. Diversity of species is an important index of organism composition structure of a community. It can not only reflect the organizing level of community, but also indirectly reflect the characteristics of community function by the relationship between structure and functionality. The change in the diversity of species during the vegetation restoration reflects the restoration degree of vegetation, and meanwhile, it's also the result of combined action of environmental evolution, species invasion and spreading, competition roles and ecological process of community (Richard et al.,1987). In this paper, $\alpha$ diversity index is chosen to study the community characteristics of 4 different types of disused lands of quarries during the initial stage of restoration, it has two meanings: (1)the number of species in the community indicates the species richness; (2)the relative density of each species in the community indicates the species evenness.

Table2. $\alpha$ diversity indexes of plant community in different types of the abandoned lands of quarry

\begin{tabular}{cccccc}
\hline Other site types & Shannon-Wiener $\left(H^{\prime}\right)$ & Simpson $(D)$ & Pielou $(\mathrm{Jp})$ & Alatalo $($ Ea $)$ & Margalef $(\mathrm{Ma}$ \\
\hline Spoil mound & 1.9833 & 0.7895 & 0.8812 & 0.7821 & 1.8951 \\
Worked-out area & 2.4822 & 0.8756 & 0.7212 & 0.7212 & 2.7624 \\
Stone-soil stack & 2.2110 & 0.8021 & 0.7414 & 0.7417 & 2.6689 \\
Terrace for crush & 0.8923 & 0.6003 & 0.7102 & 0.6988 & 0.8204 \\
\hline
\end{tabular}

As shown in Table 4, the evenness indexes of species are basically listed in an order from large to small, i.e. spoil mound $>$ stone-soil stack $>$ worked-out area $>$ terrace for crush. The species richness index of the worked-out area is the largest, but it's species evenness index is the smallest, indicating the individuals of each species in the community in the worked-out area of quarry is probably allocated unevenly; the species richness index of the spoil mound is 1.8951 , only higher than that of terrace of crush, but its species evenness index is the largest among the 4 types of disused lands, probably due to relatively low plant gathering strength in the disused land of spoil mound.

The species richness index and comprehensive diversity index tend to be consistent, the species richness index (Margalef) and comprehensive diversity index (Shannon-Wiener and Simpson) 4 types of disused lands increase from $0.8204,0.8923$ and 0.6003 to $2.7624,2.4822$ and 0.8756 respectively according to the sequence of terrace for crush, spoil mound, stone-soil stack and worked-out area. Due to the action of surface runoff, much sediment is brought to worked-out area of quarry, and meanwhile, soil seed bank is contained in the sediment, and there is a little water gushing out on the slope. All of these provide the most favorable condition for the growth of plants. High habitat diversity of the worked-out area of quarry also improves the diversity of plant community. The species richness index and (Margalef) comprehensive diversity index (Shannon-Wiener and Simpson) of terrace for crush are the lowest, indicating the severe site condition, not favorable for the growth of plants.

\section{Conclusion and discussion}

1) The soil physicochemical properties of the 4 types of disused lands of quarry measured by test indicate: the order of gravel (size: $10-1 \mathrm{~mm}$ ) contents is spoil mound $<$ worked-out area $<$ stone-soil stack < terrace for crush, 30.8\%, 52.9\%, 63.3\% and 73.9\% respectively. The nutrient conditions of the 4 types of disused lands are all very poor, the contents of organic matters, hydrolyzable nitrogen, available phosphorus and available potassium increase in the order of terrace for crush, stone-soil 
stack, spoil mound and worked-out area, the content of organic matters drops within $0.65 \% \sim 1.65 \%$, and the contents of hydrolyzable nitrogen, available phosphorus and available potassium are $1.05 \sim 3.01 \mathrm{mg} \cdot \mathrm{kg}^{-1}, 0.21 \sim 1.42 \mathrm{mg} \cdot \mathrm{kg}^{-1}$ and $1.85 \sim 4.91 \mathrm{mg} \cdot \mathrm{kg}^{-1}$ respectively. As can be seen, abandoned quarry is of an extremely poor land type, soil is the main factor restricting the natural restoration of vegetation on the disused lands of quarry. Therefore, to improve the physicochemical properties of soil and introduce propagulums is necessary to the ecological restoration of quarry.

2) The survey of plant community at quarry indicates: During the natural succession in recent 10a, drought-tolerant and anti-barren Gramineae herbaceous plants are dominant, but the woody species are relatively limited, with only 4 species of dungarunga and 3 species of shrubs, covering 17.07\% of the total number of species. Herb layer is the dominant layer at quarry and the species composition of community is relatively rich, there are 5 families, 24 genera and 27 species, among which, Gramineae and Compositae plants are the most. It can also be seen from the importance value of each species of the community that Setaria virids (L.) Beauv. in the community of the disused lands of spoil mound and terrace for crush is dominant. Compared with other communities, species with importance value $>1$ are the least, indicating the dominating advantage of Setaria virids (L.) Beauv. The reason probably lies in the fact that the two types of disused lands are usually interfered with by man. In the community of the worked-out area, the importance value of dominant species is relatively small, but the number of species with importance value $>1$ is larger, indicating the competition in the community is relatively stable, which is favorable for the growth and reproduction of other species.

3) The changes of $\alpha$ diversity indexes to four types of the abandoned lands of quarry are quite different, the descending order of the species richness indexes to different types of the abandat quarry is spoil mound $>$ stone-soil stack $>$ worked-out area $>$ terrace for crush; and the species richness index and comprehensive diversity index are in such order spoil mound $<$ spoil mound $<$ stone-soil stack $<$ worked-out area, increased from $0.8204,0.8923$ and 0.6003 to $2.7624,2.4822$ and 0.8756 . In contrast, the habitat condition of the worked-out area is the most favorable, indicating habitat diversity is also one of the necessary conditions for improving the diversity of species in the community.

4) In general, the terrace for crush features the worst performance, mainly due to its habitat condition. Terrace for crush is mainly composed of scattered gravels and stone powder, and the ground surface turns very solid when the gravels and stone powder are rolled over repetitively. And such condition isn't favorable for the growth of plants. For such abandoned lands, it's necessary to carry out some excavation engineering work to establish an environment to facilitate the growth of plants and succession. For instance, prepare some planting troughs and backfill planting soil, and then facilitate the ecological restoration of the disused lands by planting grass and trees. The study of Salonen and Setal reveals that seeds supply is a more critical factor for control of plant invasion; however, the study of disused Damiao Quarry reveals that there are only some woody and vine plants, mainly herbaceous plants. Therefore, it's advised to make the best of indigenous plants during artificial restoration, and select plant species with strong adaptability, and this is favorable for the community succession and natural vegetation restoration on the disused lands.

\section{Acknowledgements}

The project was financially supported by the International Technology Cooperation Special Project (2012DFA90500): Research on Key Technology Cooperation for Comprehensive Improvement to Acidic Pollution in Metallic Mine Dump.

\section{References}

[1] Duan Wenjun, Ren hai, Fu shenglei,et al. Natural recovery of different areas of a deserted quarry in South China. Journal of Environmental Sciences, 4 (2008):476-481. (In Chinese)

[2] Tamar M. Environmental aspects of rehabilitating abandoned quarries: Israel as a case study. Landscape and Urban Planning, 3 (2008)172-179. 
[3] Lu Yong, Liu Xiaoyu, Lu binyan,et al. Study on ecological reclamation of the deserted quarries in Jiangyin Municipality. Journal of Southwest Forestry University, 4(2010)16-20. (In Chinese)

[4] Chen Bo,Bao Zhiyi .Ecological and Landscape Restoration of Some Foreign Quarries. Journal of Soil and Water Conservation, 5(2003):71-72. (In Chinese)

[5] Wu Huan, Zhou Xing. Research on Ecological Restoration of Mining Wasteland. Journal of Guangxi Teachers Education University(Natural Science Edition, sup (2003)32-35. (In Chinese)

[6] Harris J A, Birch P, Palmer J P. Land Restoration and Reclamation: Principles and Practice. Singapore: Longman, 1996.

[7] Han Fang, Li chuanrong, Sun minggao,et al. Plant community structure at an early ecological restoration stage on an abandoned quarry in Sibao Mount. Journal of Central South University of Forestry and Technology, 2(2008)35-39. (In Chinese)

[8] Ma Keping, Liu Yuming. Measurement of biotic community diversity I, methods for $\alpha$ diversity(2). Chinese biodiversity, 4(1994) 231-239. (In Chinese)

[9] Ma Keping .Measurement of biotic community diversity I, methods for $\alpha$ diversity(1). Chinese biodiversity, 3(1994) 162-168. (In Chinese)

[10]Zhang Jindun. Quantitative Ecology. Beijing: Science Press, 2004, 77-96. (In Chinese) 